Programa de Residência Pedagógica na Licenciatura em Informática: partilhando possibilidades

\title{
RELAÇÕES ENTRE INFORMÁTICA E EDUCAÇÃO FÍSICA: INTERDISCIPLINARIDADE E PRÁXIS
}

Kaliene de Lima Tavares ${ }^{1}$, Alan Klinger Sousa Alves ${ }^{2}$

\section{PALAVRAS-CHAVE}

Educação Física;

Ensino de Informática;

Práxis. $\underline{\text { RESUMO }}$

Este capítulo tem por objetivo compartilhar experiências vivenciadas durante a regência do Programa de Residência Pedagógica desenvolvida na Escola Estadual Manoel de Melo Montenegro - Ipanguaçu/RN, no período de 28 de março a 18 de setembro de 2019. Investiga a interdisciplinaridade entre as disciplinas de Informática e Educação Física ressaltando as particularidades e semelhanças entre ambas. O capítulo realça os desafios e possibilidades da práxis interdisciplinar. Conclui que a relação entre teoria e prática por meio da participação, da metodologia criativa e investigativa, favorece os processos de ensino, aprendizagem e desenvolvimento.

\section{INTRODUÇÃO}

O Programa de Residência Pedagógica, financiado pela Coordenação de Aperfeiçoamento de Pessoa de Nível Superior (CAPES), faz parte da Política Nacional de Formação de Professores e tem como objetivo aperfeiçoar a formação prática nos cursos de licenciatura, momento em que os bolsistas residentes têm a oportunidade de desenvolver olhares reflexivos nos processos educativos envolvendo a capacitação, a ambientação, a imersão e a regência.

O capítulo foi desenvolvido a partir das experiências na Escola Estadual Manoel de Melo Montenegro - Ipanguaçu/RN no qual foi possível constatar a possibilidade de ensino e aprendizagem com o uso da informática nas aulas de Educação Física, pois a escola-campo não disponibiliza equipamentos tecnológicos como computadores, tablets e outros, para que os alunos possam utilizar durante as aulas teóricas e práticas.

Já é possível encontrar em algumas escolas brasileiras investimentos em tecnologias, mas tais recursos ainda não chegam a todos e todas. Ainda assim, mesmo que chegue o investimento, ainda há a resistência da inovação pelo setor pedagógico e pelos próprios professores.

O acesso à tecnologia é também uma inserção social que possibilita outros aprendizados e novas perspectivas, como a integração da tecnologia em sala de aula. Portanto, este trabalho realizou um estudo sobre o uso da informática nas aulas de

${ }^{1}$ Graduando do Curso Superior de Licenciatura em Informática no Instituto Federal de Educação, Ciência e Tecnologia do Rio Grande do Norte (IFRN) - Campus Ipanguaçu. E-mail: lima.kaliene95 @gmail.com

2 Professor Efetivo do Instituto Federal de Educação, Ciência e Tecnologia do Rio Grande do Norte (IFRN). Mestre em Engenharia de Software. E-mail: alan.klinger@ifrn.edu.br 


\section{Kaliene Lima \& Alan Klinger}

Educação Física contextualizando as experiências como bolsista residente do Programa de Residência Pedagógica na Escola Estadual Manoel de Melo Montenegro, em Ipanguaçu/RN.

Prensky (2012 apud Padilha, 2010) afirma que a relação dos profissionais da educação com as tecnologias é cada vez mais necessária no mundo atual. Porém, na escola ainda percebemos alguns problemas na integração das tecnologias na educação, que denota uma clara distinção de atitude, entre alunos e professores, frente às tecnologias digitais.

\section{METODOLOGIA}

A pesquisa é fundamentada numa abordagem teórico-metodológica, refletindo sobre as práticas pedagógicas entre o ensino de informática e a Educação Física. A pesquisa pauta-se numa investigação de campo com as experiências vivenciadas nas ações do Programa Residência Pedagógica, na Escola Estadual Manoel de Melo Montenegro, na cidade de Ipanguaçu/RN.

Durante o período de capacitação foi realizada a formação através de encontros semanais e aulas de videoconferência, por meio do youtube no canal PNTV, distribuídos em onze vídeos com temas diversificados, abordados por especialistas na área acadêmica que trouxeram discussões significativas que muito contribuíram para a elaboração do relatório final dos bolsistas residentes.

Foram realizados encontros na Escola Estadual Manoel de Melo Montenegro, escola-campo, a fim de nos ambientar de sua estrutura física e pedagógica para melhor desenvolvermos nossas atividades.

Nessa etapa foram desenvolvidas observação e regência de classe. Incluindo o planejamento e execução pedagógica que envolve: empregar estratégias para resolver desafios, aumentar as possibilidades de aprendizagem das práticas corporais e a ampliação do acervo cultural nesse campo.

A regência de classe destaca desde a formação profissional, planejamento coletivo e individual relacionando a teoria-prática. Nesse período, o bolsista residente acompanhou um professor em sala de aula, participando do planejamento, observação e desenvolvimento da regência.

Com relação à regência, foi notória a conexão da Informática com a Educação Física ao perceber que os jogos são o destaque nas aulas, sendo possível organizar o planejamento referenciando o esporte e inserindo a informática.

Sobre o ensino da Educação Física, Testa (2011) aponta que a disciplina vem ganhando destaque como prática pedagógica por meio de instâncias e compreensões pedagógicas, como também vem intensificando suas metodologias a fim do fortalecimento do ensino e aprendizagem, referenciando exemplos práticos nas aulas.

Tomando como base essa ampliação do ensino da Educação Física, a organização das aulas decorreu pela análise dos jogos de maneira lúdica enfatizando a cooperação e colaborando para a otimização em quadra, especificamente na modalidade do voleibol. 


\section{Kaliene Lima E Alan Klinger}

Segundo Testa (2011, s/p), o ensino de técnicas e dos fundamentos básicos do esporte é importante, no entanto deve-se considerar também o diálogo em grupo: "dialogar na questão das técnicas, exemplo: o professor pergunta: por que temos que arremessar desta forma, e por que não de outra?".

Para Leal (2011), a Educação Física é construída no fazer por meio da experimentação e do conhecimento e, ainda, a escola deve estar aberta não apenas para manusear os instrumentos tecnológicos, mas antes permitir a reflexão na ação e na aprendizagem. Ademais, é fundamental incorporar, de forma organizada, as principais questões que o professor de Educação Física e o professor do projeto de Informática na escola devem considerar no desenvolvimento de seu trabalho, subsidiando as discussões, os planejamentos e as avaliações.

As experiências foram desenvolvidas da seguinte forma: $1^{\mathrm{a}}$ etapa: observação da escola-campo; $2^{\mathrm{a}}$ etapa: planejamento; $3^{\mathrm{a}}$ etapa: observação da sala de aula incluindo as aulas práticas e, por último, a $4^{\mathrm{a}}$ etapa: a regência.

\section{DESENVOLVIMENTO}

$\mathrm{Na}$ realidade das escolas da rede pública, há alunos que apresentam dificuldades de aprendizagem motora e de disciplina, sendo necessária uma intervenção pedagógica diferenciada que desperte o seu interesse. Sugere-se aqui a união da tecnologia com a Educação Física para que os alunos obtenham uma maior concentração nas tarefas a eles solicitadas. Considera-se também que nem todos têm acesso às tecnologias em suas casas. Será também um recurso para a concretização da aprendizagem ao longo do tempo, desenvolvendo o uso da tecnologia nas aulas de Educação Física como instrumento facilitador da aprendizagem. (LEAL, 2011).

Sabemos que a disciplina de Educação Física é exigida como qualquer outro componente que faz parte da matriz curricular, mas ainda há em algumas escolas posicionamentos que enfatizam ser essa disciplina apenas um complemento na carga horária do curso. No entanto, há uma possibilidade de inserirmos a tecnologia juntamente com a Educação Física a fim de possibilitar relações de ensino e aprendizagem durante as aulas teóricas e práticas.

Sendo assim, concordamos com Moran (1995 apud Leal, 2011), quando afirma que o relacionamento da tecnologia com a Educação Física transforma alguns contextos da inter-relação com o mundo, da percepção da realidade e da interação com o tempo e o espaço. Devemos estar abertos para as mudanças com as tecnologias, utilizando-as não apenas como ferramentas nas escolas, mas também como ações em projetos que viabilizem a aprendizagem e levem uma ampliação da interação desta com os discentes e docentes.

Assim, os jogos nas aulas práticas de Educação Física concorrem, pela contextualização, para a aprendizagem dos alunos, uma vez que a relação aluno conhecimento - brincadeira - seja utilizada, pedagogicamente, no ato de aprender. Entendemos aqui o lúdico na perspectiva de que os jogos e as brincadeiras 


\section{Kaliene Lima E Alan Klinger}

promovem as maiores aquisições nos alunos ampliando a compreensão acerca do ensino de Educação Física.

Na visão de Piaget (1982 apud Leal, 2011), a aplicação do jogo forma expressão e condição para o desenvolvimento infantil, posto que as crianças ao jogarem assimilam e transformam a realidade e, para Vygotsky (1989 apud Leal, 2011), o desenvolvimento ocorre por meio de um processo considerando as funções psicológicas. O sujeito, para ele, é interativo, diferenciando-se de Piaget por não estabelecer fases para explicar o desenvolvimento.

Considerando o processo de ação/reflexão/reação, as atividades propostas pretendem agir no educando, levando-o a interagir com dois elementos envolvidos nas ações pedagógicas: tecnologia e Educação Física. Buscamos aprimorar a cultura lúdica (jogo e brincadeira) por meio das experiências adquiridas anteriormente, numa fusão com as do presente facilitando o exercício dos processos mentais.

Diante disso, podemos considerar a opinião de Vygotsky (1989 apud Leal, 2011) em relação ao jogo, quando estabelecemos o resgate de nossa cultura possibilitando uma construção e reconstrução da identidade individual e coletiva, baseada na experiência.

As ações práticas entre o ensino da Educação Física e da informática é desafiadora e significativa. Desafiadora por ter qualidades que contribuem para a formação crítica e ampliada, necessitando de maiores estudos e, ao mesmo tempo significativa por abranger duas áreas de estudo a princípio distintas, mas que se relacionam quando o objetivo é o ensino e aprendizagem.

As ações com o uso da informática nas aulas de Educação Física ocorreram no período de 28 de março a 18 de setembro de 2019, quando participaram a professora titular da disciplina, os alunos da escola-campo e bolsista residente do Programa de Residência Pedagógica. A regência relacionou o uso de fluxogramas utilizando a lógica computacional com o objetivo de marcar o tempo e otimizar os passos dos jogos especificamente no voleibol feminino, de forma a planejar e aperfeiçoar os treinos.

A lógica computacional foi destaque ao relacionar as práticas de Educação Física no processo de otimização das jogadas durante os treinos. Assim, antes dos treinamentos, foi realizado um estudo sobre o último exercício a fim de melhorar os arremessos, o ataque e o contra-ataque, ocasião em que o pensamento computacional realizou uma revisão das ações desenvolvidas na quadra.

O pensamento computacional é destaque pela infinidade de aplicações. Como pontua André (2018, p. 97), envolve aproveitamentos em sistemas, processos, objetos, algoritmos, problemas, soluções, entre outros. Assim, faz-se necessário entender que o "[...] pensamento computacional, na sociedade atual, produz um importante movimento pedagógico denominado ciência, tecnologia e sociedade."

Já as ações dos diferentes processos do jogo do voleibol foram observar e analisar os passos realizados pelas levantadoras, a fim de obter desempenho satisfatório em quadra por meio das táticas de decisão. Como bem menciona Bordini (2015, p. 24): 
[...] a tomada de decisão (TD) é o processo pela qual as escolhas são feitas, estando este tema entre os mais investigados em diferentes áreas de estudo. No meio esportivo, TD tem sido objeto de estudo de pesquisadores do campo de Comportamento Motor, cujo desafio é esclarecer como indivíduos habilidosos tomam suas decisões e como adquirem tal capacidade.

Neste sentido, as ações de decisão antes dos treinos durante as experiências com as disciplinas de Informática e Educação Física foram realizadas por meio da criação de fluxogramas, que é destaque na pesquisa de Azevedo (2016) ao dinamizar o fluxograma como ferramenta de mapeamento, visto pela autora como uma análise de ação atual buscando a melhoria da realidade pesquisada, que no nosso estudo o objeto foi aperfeiçoar as jogadas em quadra, em especial o ataque e o contra-ataque.

\section{RESULTADOS E DISCUSSÕES}

Como campo interdisciplinar, os espaços de intervenção da Educação Física vão além da escola e espaços institucionalizados, ainda que seu primordial compromisso passe por estratégias escolares e políticas públicas de educação, o que inclui sua abordagem na formação inicial e continuada de professores e profissionais da Educação Física, para que seja garantida a reflexão e prática social esclarecida frente às relações com a mídia e novas tecnologias.

O processo de ambientação ocorreu entre agosto a setembro de 2018, com a formação dos bolsistas residentes por meio de cursos promovidos pelo Instituto Federal do Rio Grande do Norte, objetivando apresentar o Programa de Residência Pedagógica e as atividades a serem desenvolvidas durante a etapa de imersão.

Especificamente na escola-campo, o processo de ambientação do bolsista residente abrangeu os aspectos estruturais, organizacionais e pedagógicos, objetivando a caracterização da realidade da escola.

Os processos de imersão de classe e regência incluíram o planejamento, a execução e a intervenção pedagógica, destacando a linguagem própria da tecnologia de forma a potencializar a pesquisa, a socialização, a produção e as relações teoria e prática. Estando atento a este propósito, as práticas da regência remeteram-se por meio da análise das jogadas utilizando o fluxograma, relacionando as disciplinas de Educação Física com a informática.

O período de imersão na escola-campo, que precedeu o da regência, foi caracterizado pelo momento em que o bolsista residente se reunia com o professor preceptor e escolhia um professor de qualquer disciplina da escola-campo, preferencialmente a de Informática, mas como essa escola não possui nem professores nem laboratórios de informática, outra disciplina foi escolhida, no caso Educação Física. Nesse período, foram feitos os planejamentos das aulas com o professor e a observação em sala de aula, além do momento em que o bolsista residente ministrou aulas de informática juntamente com o componente curricular selecionado. 


\section{Kaliene Lima \& Alan Klinger}

Outro aspecto que merece destaque na escola-campo foram as ações referentes à feira de ciências, onde todos os alunos participam e com a supervisão dos professores, apresentam diversos projetos relacionando a teoria com a prática, enfatizando os experimentos e a interdisciplinaridade entre as disciplinas.

No que diz respeito à disciplina Educação Física, destacamos o mapeamento das jogadas antes de cada jogo, durante a preparação do torneio de voleibol. Assim, várias técnicas foram criadas a fim de identificar os erros no ataque e no contraataque, de modo que as decisões eram tomadas e ajustadas no próximo jogo, diminuindo os erros e organizando cada arremessadora em quadra.

\section{CONSIDERAÇÕES FINAIS}

A experiência de participar do Programa de Residência Pedagógica foi importante para o bolsista residente, pois possibilitou, de acordo com as práticas educacionais desenvolvidas, que houvesse a capacitação, a ambientação, a imersão e a regência na escola-campo, destacando o diálogo do ensino de informática com a disciplina Educação Física.

A interdisciplinaridade entre a informática e a Educação Física fez das aulas um grande aprendizado, pois trabalhamos as brincadeiras, os jogos, usando tecnologias para aprimorar aulas teóricas e práticas, fazendo com que os alunos se sentissem mais à vontade na participação das aulas, valorizando as brincadeiras, jogos e a humanização, tendo uma aprendizagem significativa nas relações de saberes e fazeres.

Como afirma Freire (2013, p. 32),

Não há ensino sem pesquisa e pesquisa sem ensino. Esses fazeres se encontram um no corpo do outro. Enquanto ensino continuo buscando, reprocurando. Ensino porque busco, porque indaguei, porque indago e me indago. Pesquiso para constatar, constatando, intervenho, intervindo educo e me educo. Pesquiso para conhecer o que ainda não conheço e comunicar ou anunciar a novidade.

Concordamos com Paulo Freire ao vincular o ensino, a pesquisa e a aprendizagem ao desenvolvimento do educando. Isto foi possível vivenciar na imersão que tivemos na escola-campo, fazendo uso da interdisciplinaridade do ensino da Educação Física com a Informática, conforme demonstramos nesse capítulo.

\section{REFERÊNCIAS}

ANDRÉ, Claudio F. O pensamento computacional como estratégia de aprendizagem, autoria digital e construção da cidadania. Revista Digital de Tecnologias Cognitivas, n. 18, jul./dez. 2018, p. 94-109. Disponível em: 


\section{Kaliene Lima \& Alan Klinger}

https://www.pucsp.br/pos/tidd/teccogs/artigos/2018/edicao_18/teccogs18_artig o05.pdf. Acesso em: 01.11.2019.

AZEVEDO, Irene Conceição Gouvêa de. Fluxograma como ferramenta de mapeamento de processo no controle de qualidade de uma indústria de confecção. In: CONGRESSO NACIONAL DE EXCELÊNCIA EM GESTÃO, 12.. 2016, [s.l.]. [Anais], [s.n]. Disponível em: http://www.inovarse.org/sites/default/files/T16_M_024.pdf. Acesso em: 01.11.2019.

BORDINI, Fábio Luís. Análise das ações dos levantadores nos diferentes processos de jogo no voleibol. Tese de doutorado em Educação Física. Universidade Estadual de Londrina. Centro de Educação Física e Esporte, Programa de Pós-Graduação em Educação Física. Londrina, 2015. Disponível em: http://www.uel.br/grupopesquisa/gepedam/prod_cientifica/teses_dissert/td1.pdf. Acesso em: 01.11.2019.

CARVALHO, Arivan Santos de; et al. O ato de planejar e a importância do planejamento na organização do profissional de Educação Física. EFDeportes.com, Revista Digital. Buenos Aires, 2011. Disponível em: https://www.efdeportes.com/efd156/o/-ato-de-planejar-naeducacao-fisica.htm Acesso em: 12 de outubro de 2019

CARVALHO JUNIOR, Arlindo Fernando Paiva de. As tecnologias nas aulas de educação física escolar. Vitória, ES, 2015.

CAZELOTO, Edilson. Inclusão digital: uma visão crítica. São Paulo: Editora Senac, 2008.

FERNANDO, Arlindo. As tecnologias nas aulas de Educação Física escolar. Qualis, Capes. 2017. Disponível em: https://educacaopublica.cecierj.edu.br/artigos/17/1/as-tecnologiasnas-aulas-de-educao-fsica-escolar Acesso em: 03 de outubro de 2019.

FREIRE, P. Pedagogia da Autonomia: saberes necessários à prática educativa. São Paulo: Paz e Terra, 2013.

GEMENTE, Flórence R. Faganello; MATTHIESEN, Sara Quenzer. A educação física e as tecnologias de informação e comunicação: desafios e possibilidades. Universidade Federal de Goiás - Goiana (UFG). Disponível em: https://pt.scribd.com/document/230585242/AEducacao-Fisica-e-as-Tecnologias-de-Informacao-e-Comunicacao-Final Acesso em: 12 de outubro de 2019.

LEAL, Helaine Aparecida Lopardi. Projeto - Informática e educação física: a inserção do uso das tecnologias de informação e comunicação. Juiz de Fora - MG, 2011. Disponível em: https://informaticaeesvp.blogspot.com/2012/06/projeto-informatica-e-educacao-fisica.html Acesso em: 03 de outubro de 2019.

OLIVEIRA, Dalila de Andrade. Gestão Democrática da Educação: Desafios Contemporâneos.7. ed. Petrópolis, RJ: Vozes, 1997.

PADILHA, Maria Auxiliadora Soares; ABRANCHES, Sérgio Paulino. Pesquisando e aprendendo sobre o uso das tecnologias da informação e comunicação como recurso 
didático-pedagógico para o ensino nas escolas da rede pública de ensino fundamental e médio. Relatório de Projeto de Extensão. PROEXT: Universidade Federal de Pernambuco, 2010.

Disponível em: http://www.anpae.org.br/IBERO_AMERICANO_IV/GT4/GT4_Comunicacao/MariaAuxil iadoraSoaresPadilha_GT4_integral.pdf Acesso em: 13 de outubro de 2019.

PEREIRA, José Carlos Rodrigues; SILVA, Samira Fayez Kfouri da. Educação e tecnologias na perspectiva da gestão escolar. Governo do Paraná. Disponível em: http://www.diaadiaeducacao.pr.gov.br/portals/pde/arquivos/2499-6.pdf Acesso em: 12 de outubro de 2019.

TESTA, Wagner Luiz. Metodologias de ensino em Educação Física. In: EFDeportes.com, Revista Digital. Buenos Aires, Ano 16. No 159. Agosto de 2011. Disponível em: https://www.efdeportes.com/efd159/metodologias-de-ensino-em-educacao-fisica.htm. Acesso em: 03.11.2019. 